ORNL/TM-2000/46

\title{
Dynamic Pressure of Liquid Mercury Target During 800-MeV Proton Thermal Shock Tests
}

S. W. Allison, J. B. Andriulli, M. R. Cates, D. D. Earl, J. R. Haines, F. X. Morrissey, C. C. Tsai

Oak Ridge National Laboratory

Oak Ridge, Tennessee 37831-8058 USA

S. Wender

Los Alamos National Laboratory Los Alamos, New Mexico 87545 USA 


\section{DISCLAIMER}

This report was prepared as an account of work sponsored by an agency of the United States Government. Neither the United States Government nor any agency thereof, or any of their employees, makes any warranty, expressed or implied, or assumes any legal liability for responsibility for any third party's use, or the results of such use, of any information, apparatus, product or process disclosed in this report, or represents that its use by such third party would not infringe privately owned rights. Reference herein to any specific commercial produce, process, or service by trade name, trademark, manufacturer, or otherwise, does not necessarily constitute or imply its endorsement, recommendation, or favoring by the United States Government or any agency thereof. The views and opinions of authors expressed herein do not necessarily state or reflect those of the United States Government or any agency thereof. 


\section{DYNAMIC PRESSURE OF LIQUID MERCURY TARGET DURING 800-MeV PROTON THERMAL SHOCK TESTS}

J. B. Andriulli, S. W. Allison, M. R. Cates, D. D. Earl, J. R. Haines, F. X. Morrissey, and C. C. Tsai

Oak Ridge National Laboratory

P. O. Box 2008

Oak Ridge, TN. 37831

(423)-576-2725

\section{ABSTRACT}

Described here are efforts to diagnose transient pressures generated by a short-pulse (about 0.5 microseconds) high intensity proton $\left(\sim 2 * 10^{14}\right.$ per pulse $)$ beam. Proton energy is $800-\mathrm{MeV}$. The tests were performed at the Los Alamos Neutron Science Center - Weapons Neutron Research (LANSCE-WNR). Such capability is required for understanding target interaction for the Spallation Neutron Source project as described previously at this conference. ${ }^{1-4}$ The main approach to effect the pressure measurements utilized the deflection of a diaphragm in intimate contact with the mercury. There are a wide variety of diaphragmdeflection methods used in scientific and industrial applications. Many deflection-sensing approaches are typically used, including, for instance, capacitive and optical fiber techniques. It was found, however, that conventional pressure measurement using commercial pressure gages with electrical leads was not possible due to the intense nuclear radiation environment. Earlier work with a fiber optic strain gauge demonstrated the viability of using fiber optics for this environment. ${ }^{3,4}$

\section{BACKGROUND TO PRESSURE MEASUREMENT}

The pressure sensor design selected for this application was driven by several factors: the magnitude and duration of the pressure waves, the need for both high and low pressure measurement, and the need to use standardized, readilyavailable components. Two pressure sensors using diaphragms that were deflected according to the applied pressure were selected. The diaphragms were made from stainless steel. Diaphragm size and thickness were determined based on modeling which examined the tradeoffs between sensitivity, dynamic range, and response time. Deflection measurement was effected with a modified commercial fiber optic strain measurement system described later in this report. For both sensors, a mechanical stop prevented the diaphragm from flexing past the yield point. This corresponded to pressures of $17 \mathrm{MPa}(2,500 \mathrm{psi})$ and $0.7 \mathrm{MPa}(100 \mathrm{psi})$ for the high- and low-pressure sensors, respectively. This is the upper bound of their measurement capability. The specific purpose of the high-pressure sensor was to diagnose the initial highpressure transient due to the instantaneous deposition of

\author{
S. Wender \\ Los Alamos National Laboratory \\ P. O. 1663 \\ Los Alamos, NM. 87545 \\ (505)-667-1344
}

energy in the mercury fluid. The purpose of the low-pressure sensor was to investigate the possibility of detecting cavitation. These oscillations are predicted to occur at later times, after the expected first thermal shock induced expansion.

There was a parallel effort to investigate the use of phosphor fluorescence as a pressure diagnostic. ${ }^{5}$ A phosphor was selected exhibiting approximately a one per cent signal increase per $10 \mathrm{MPa}$. It was thought that this method might provide very rapid response to pressure. The fluorescence was stimulated by a short-pulsed $\mathrm{N}_{2}$ laser of 3 ns duration. The results are summarized as follows. By examination of the fluorescence decay, no pressure fluctuations were discernible within the considerable noise that characterized the test. The minimum pressure observable would have been about $50 \mathrm{MPa}$. The dominant noise apparently was shot noise. This type of noise scales as the square root of the number of phosphorfluorescence photons arriving at the photodetector. In the future, shot noise will be reduced by increasing the amount of fluorescence arriving at the photomultiplier detector and by decreasing the response time of the detection system.

We also observed occasional intense, short spikes in addition to the fluorescence signal from the phosphor. This is evidently some kind of radiation induced scintillation either of the phosphor or fiber. In such instances, however, these spikes were easily distinguishable from the laser-stimulated phosphor emission. When the fluorescence signal was subsequently improved by better laser-to-fiber coupling, the spikes were much weaker compared to the fluorescence. A more detailed report of the phosphor testing is in preparation.

It was encouraging that both phosphors, europium-doped lanthanum oxysulfide and manganese-doped magnesium fluorogermanate, survived the entire test, about 40 shots, without noticeable degradation. The proton beam itself generated fluorescence that may be used for diagnostic purposes.

\section{FABRY-PEROT SENSING DESCRIPTION}

In order to measure the diaphragm deflection, a commercial fiber optic strain sensor was modified. The sensor was an F\&S Inc. Fiber Optic Strain Sensor (FOSS) system . The FOSS system consists of a light source at $1310 \mathrm{~nm}$ that illuminates a 
single-mode optical fiber and a photodiode to detect light returning from the fiber. The input end fiber is terminated with an FT connector which mates with the FOSS system. The sensor end normally terminates in a specially designed capillary tubing for strain sensing purposes. The use of F\&S hardware for strain sensing on two SNS targets is described elsewhere $e^{6-7}$. For pressure sensing, the output end of the fiber is removed from the tubing and located a fixed distance from a diaphragm. This diaphragm flexes when the fluid on the opposite side increases in pressure. As the distance between the fiber and the diaphram changes, the amount of light reflected back into the fiber changes as well. Because the output face of the fiber is partially reflecting, a Fabry-Perot cavity is formed by it and the shiny, reflective diaphragm surface. Figure 1 illustrates the fiber in relation to the diaphragm.

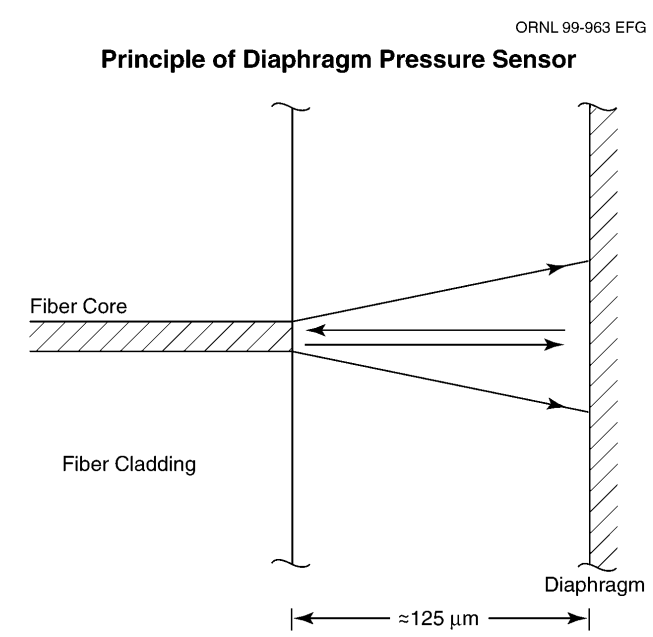

Figure 1. Fiber Arrangement.

The light reflected from the diaphragm surface recombines and interferes with the light reflected by the fiber end such that the return signal varies sinusoidally with a period of $1 / 2$ of the incident wavelength of $1310 \mathrm{~nm}$. This approach is much more sensitive than non-interferometric methods. The light signal travels to the FOSS system where it is detected. The unit's output is an electrical analogue of this signal and is directed to a digital oscilloscope which digitizes it. An IEEE 488 interface connection with a personal computer provides the means to store and subsequently analyze the signal.

\section{PRESSURE SENSOR AND CALIBRATION}

Figures 2 shows the high and low pressure sensors. They appear identical externally. Figure 3 is a side view of one of them. To construct them, first, standard vacuum flanges were machined to accommodate a 3/8" pipe. At the end of this pipe, a 3/8" Cajon ${ }^{\mathrm{TM}}$ fitting is applied in the normal manner. As it tightens, it secures the diaphragm, clamping it against the end of the pipe. The fitting and diaphragm are seen in the foreground of the figures. The optical fiber is potted with epoxy inside a smaller tube which slides inside of the $3 / 8$ "

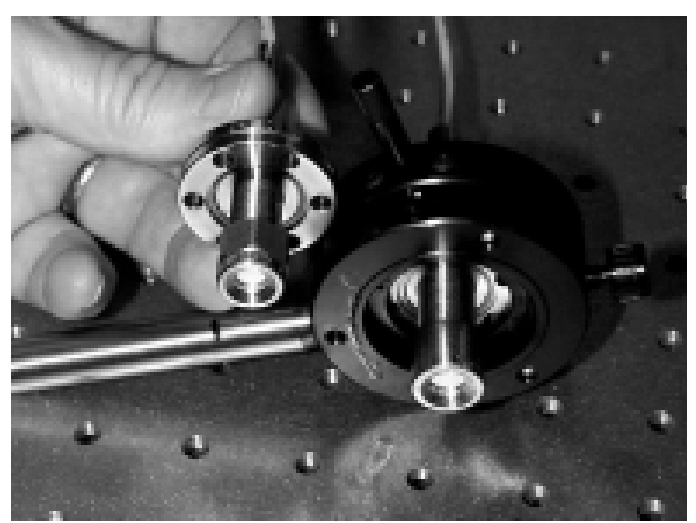

Figure 2. Two diaphragm sensors.

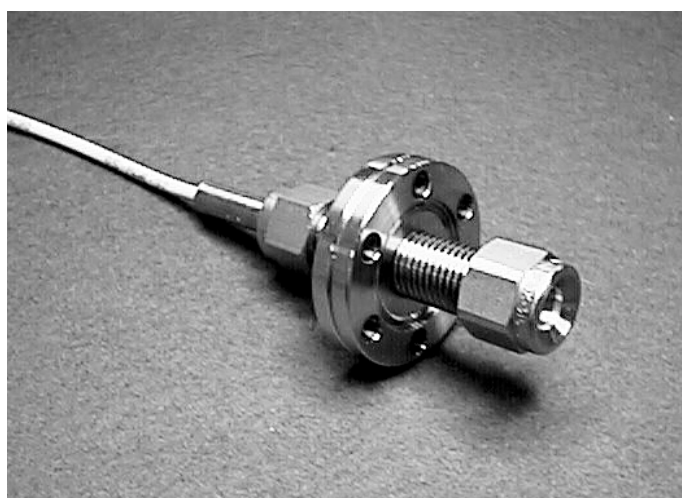

Figure 3. Side View of Pressure Sensor.

tubing. Another Cajon ${ }^{\mathrm{TM}}$ fitting in the back allows for tightening and setting of the position of this inner tube and thus establishing a fixed distance between the fiber and the back surface of the diaphragm. The flange of the sensors seen in the figures is bolted to the target such that the sensing end protrudes into the mercury.

The sensors were calibrated using a hydraulic pump as the pressure source. An instrument known as the Fiberscan 2000, also made by F\&S, was used to determine the fiber-todiaphragm gap. It functions similar to the FOSS system for strain or displacement measurements. In this instrument, a broad band light source illuminates the fiber. This device detects and analyzes several wavelengths of the return signal. Internal processing provides for displaying the results as strain or gap distance, as selected by the user. This component cannot be used for dynamic measurements as a reading is updated only every second. On the other hand, the FOSS system provides 
real time analog output which at the time of the experiment was capable of a response of in excess of $100 \mathrm{kHz}$.

High Pressure Sensor: For the high pressure sensor, the gap between the fiber and the diaphragm was $260 \mu \mathrm{m}$ and the active diameter of the diaphragm (taking account of where it was clamped) was $7.9 \mathrm{~mm}$. Its thickness was $254 \mu \mathrm{m}$. As the diaphragm was displaced, the sinusoidal peak-to-peak voltage was about $0.7 \mathrm{~V}$. Figure 4 shows a plot of diaphragm displacement versus pressure for two instances. Below 17 $\mathrm{MPa}$, the calibration is repeatable and it is seen that a pressure of $7 \mathrm{MPa}$ causes a diaphragm deflection of about $50 \mu \mathrm{m}$. For small deviations, the response is approximately 30 V/MPa. When the pressure exceeds about $17 \mathrm{MPa}(2500$ psi), there is evidently some permanent deformation of the diaphragm. This is evidenced by the decreased slope of the curve showing data taken to $35 \mathrm{MPa}$.

Low pressure sensor: A high sensitivity pressure sensor which functioned at low pressure was fabricated from thinner stainless steel stock. It was constructed with a $160 \mu \mathrm{m}$ air gap and diaphragm thickness of 51 microns and $7.9 \mathrm{~mm}$ in diameter. For small displacements, the response was about $5000 \mathrm{~V} / \mathrm{MPa}$. The calibration curve is shown in Figure 5. Data was acquired by cycling up in steps of about $70 \mathrm{kPa}(10$ psi). It is evident that the diaphragm was not flexed past its elastic limit. A pressure of about $140 \mathrm{kPa}(20 \mathrm{psi}$ ) causes the diaphragm to deflect about $25 \mu \mathrm{m}$. For the LANSCE test, the diaphragm was prevented from flexing at pressures greater than 1.0 $\mathrm{MPa}(150 \mathrm{psi})$ in order to preserve the sensor.

\section{RESULTS OFPRESSURE MEASUREMENT}

Figure 6 shows a sketch of the back end of Target A (TA). It is a bullet-shaped container of stainless steel, $10 \mathrm{~cm}$ in diameter, about $15 \mathrm{~cm}$ long, and with a $5-\mathrm{cm}$ radius hemispherical shell at the forward end. The high and low pressure sensors were located at flange P3 and P4, respectively. Over the course of the test, the target was irradiated over thirty times with a proton beam. All data sets were labelled sequentially such that TA-12 indicates proton shot number 12 for Target A. For the high pressure diaphragm sensor, measurements were made for pulses TA-12 to TA-14 and pulses TA-25 through TA-31. For the former group, the FOSS system with frequency response of approximately $100 \mathrm{kHz}$ was used. Subsequent to the test, it was discovered that the response of another FOSS system which was used for the second set of tests was, unfortunately, only about $20 \mathrm{kHz}$ (This was due to some internal electronic settings inside the unit. The settings were corrected after this series of tests). For each of shots TA-12 to TA-14, the incident number of protons was $2.3 \times 10^{13}$.
The analysis of this data is very difficult. Keep in mind that as the distance of the gap changes (monotonically), the detected signal varies sinusoidally. Once a local maximum in pressure is reached, signal from that point will continue a sinusoidal dependence, simply retracing the part of the cycle it was in. In order to estimate the maximum displacement, the point of this reversal must be determined. The displacement is the total number of cycles (ie. fringes) times half the wavelength of the light source. For slowly varying signals, identifying the turnaround points can be straightforward. For much of the rapidly fluctuating data acquired in this test, reliable determination of the turning point is not possible. There are several useful observations that can be made, however.

Figure 7 shows time versus diaphragm displacement for TA- 12 for a period of about $14 \mathrm{~ms}$ after the shot. The signal varies more rapidly at early times than later times. This means the pressure rises and decreases more rapidly at earlier times, whatever the magnitude may be. Clearly the signal versus time as seen in the figure is complex, rendering determination of the turn-around points very difficult for most of the signal. If the signal reached a maximum or minimum, that would have meant that the physical limit of flexure had been reached. This was not the case, therefore, it is a safe assumption that the pressure never exceeded $17 \mathrm{MPa}$, the pressure at which a physical stop prevents further flexure.

A comparison of data from TA-12-14 shows that the sensor response is reproducible. This is seen in Figure 8. The data of TA-12 and TA-13 were not taken for as long a period of time after the shot as TA-14, as it turned out. This is the reason for the difference in length of each of the plots in that figure. Figure 9 shows data from shot TA-14 from the time period of about 25 to $90 \mathrm{~ms}$ after the shot. The data for the first $25 \mathrm{~ms}$ is similar to that above for TA-12. But during the later time, as is depicted in Figure 9, the pressure has decreased to where the signal varies within the peak-to-peak sinusoidal-displacement period. The maximum and minimum signal are less than the peak-to-peak signal for this sensor. Thus, in this region the signal can be processed using an appropriate arcsin relationship between the time and the displacement. Then, noting from the calibration data that the dependence is $0.14 \mathrm{kPa} / \mathrm{nm}$, a plot of pressure versus time is obtained. The processed signal shown in Figure 9 reveals the pressure ranging from -5 to $15 \mathrm{kPa}$ and gradually decaying to a few $\mathrm{kPa}$. The fact that it is not precisely zero means that the diaphragm, once it ceased vibrating, returned to a final position that was different by a few nm.

Figure 10 shows representative data for the low-operating pressure, high sensitivity sensor. It is seen that, for pulse TA35 , for the first $1 \mathrm{~ms}$ the sensor quickly reaches a maximum and swings to the opposite extreme. This means the diaphragm during this portion of test flexed to its physical limits. After 
that time, the signal varied by a volt or less. For times after 1 $\mathrm{ms}$, the voltage axis could be scaled by the $5000 \mathrm{~V} / \mathrm{MPa}$ calibration factor to yield pressure versus time as seen in the figure. The meaning of these sub-kPa pressure fluctuations are difficult to assess. At very long times, up to $16 \mathrm{~ms}$, pressure waves are detectable, but are very low in amplitude.

\section{CONCLUSIONS}

1. Pressure-related data was acquired in the high radiation environment produced by the proton beam and mercury target. Results for the high pressure sensor show that the pressure never exceeds $17 \mathrm{MPa}$. For the low pressure sensor, the pressure exceeded $0.7 \mathrm{MPa}$ for the first approximately 0.5 millisecond and fluctuated rapidly at a fraction of one $\mathrm{kPa}$ over the ensuing $16 \mathrm{~ms}$.

2. No spurious signals such as would be produced by radiation-induced scintillations were detected.

3. There was no discernible signal degradation due to the high radiation.

4. As expected, a fast time response is required. The fastestresponding system with a bandwidth of about $100 \mathrm{kHz}$ produced features that were not revealed with the slower units at $20 \mathrm{kHz}$.

5. After about $30 \mathrm{~ms}$, if not earlier, pressure fluctuations decrease to $15 \mathrm{kPa}$. By $90 \mathrm{~ms}$, the mercury pressure has completely settled down.

6. The need for a system which is easier to calibrate and which automatically analyzes signals was underscored.

\section{FUTURE ACTIVITIES}

A system is presently being tested which has on-board processing and hopefully improved signal-to-noise and sensitivity for this type of application. Accompanying software may provide the means to achieve, by postprocessing of the data, a response of about $1 \mathrm{MHz}$. benefited by the use of the LANSCE-WNR facility that is funded by the U. S. Department of Energy under contract W7405-ENG-36. Research at ORNL was sponsored by the Office of Energy Sciences for the U. S. Department of Energy under contract DE-AC05-96OR22464 with Lockheed Martin Energy Research Corp.

\section{REFERENCES}

1. J. R. Haines, T. A. Gabriel, and T. G. McManamy, "Overview of the Target Systems for the Spallation Neutron Source", Presented in the $2^{\text {nd }}$ International Topical Meeting on Nuclear Applications of Accelerator Technology, Proceedings of AccApp 98, p. 222 (1998).

2. J. R. Haines, D. D. Earl, and C. C. Tsai, "Summary of Mercury Target Thermal Shock Tests Conducted at Accelerator Facilities in FY 1997," Spallation Neutron Source Target Systems Report SNS/TSR-0041, December, 1998.

3. D. D. Earl, S. W. Allison, C. C. Tsai, and J. R. Haines, "Improved Fiber Optic Pressure and Strain Sensing Techniques for Use in High Radiation Environment", Presented in the $2^{\text {nd }}$ International Topical Meeting on Nuclear Applications of Accelerator Technology, Proceedings of AccApp 98, p. 665. (1998)

4. C. C. Tsai, D. D. Earl, S. W. Allison, and J. R. Haines, "Dynamic Fiber Optic Sensors Under Intense Radioactive Environments," ibid, p. 658. (1998)

5. S. W. Allison and G. T. Gillies, "Remote Thermometry with thermographic phosphors: Instrumentation and applications," Rev. Sci. Inst. Vol. 68(4), pp2615-2650, 1997.

6. C. C. Tsai, J. B. Andriulli, S. W. Allison, M. R. Cates, D. D. Earl, J. R. Haines, F. X. Morrisey, "Dynamic Strain and Pressure Measurements of a Mercury Target Under Thermal Shock Tests", in this proceedings.

7. M. R. Cates, D. D. Earl, C. C. Tsai, S. W. Allison, J. R. Haines, F. X. Morrisey, and J. B. Andriulli "Dynamic Strain on a Mercury Target Vessel During $800-\mathrm{MeV}$ Proton Thermal Shock Tests," ORNL/TM-2000/47.

\section{ACKNOWLEDGEMENTS}

The authors would like to thank Greg Chaparro, Lloyd Hunt, and accelerator staff members at LANL for their support in enabling the tests at the LANSCE-WNR facility. The goals of the program of which the present work is a part were 


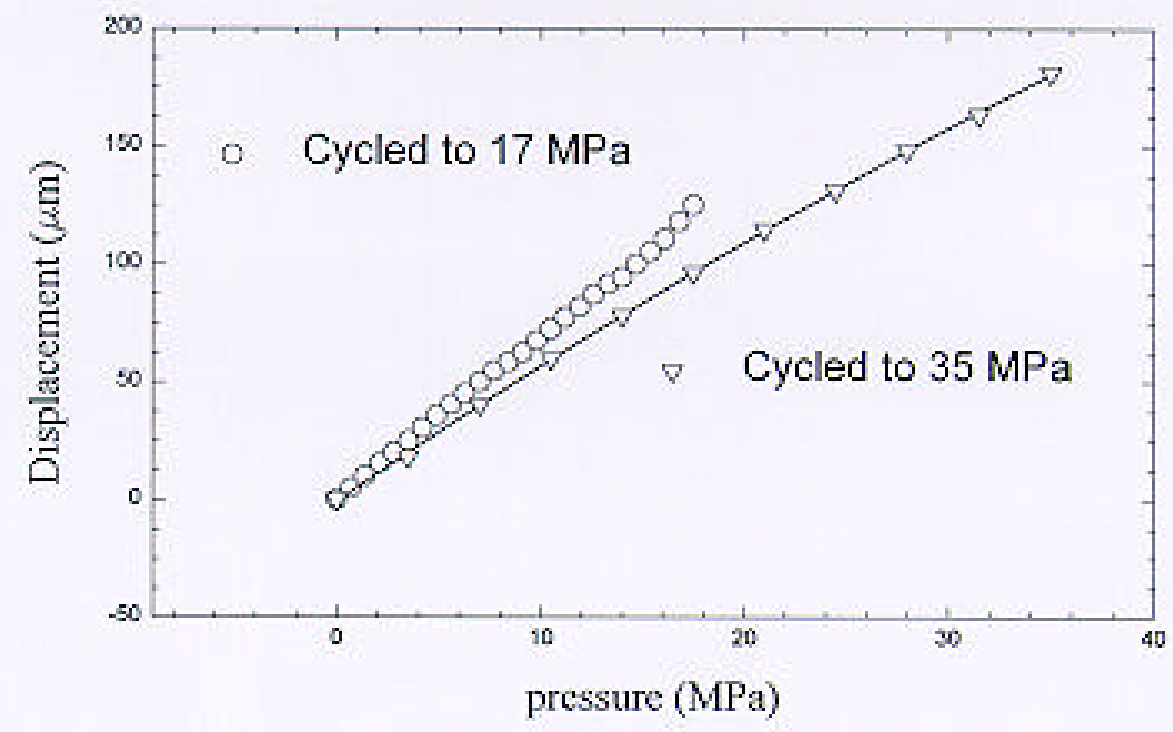

Figure 4. High pressure sensor - pressure versus displacement.

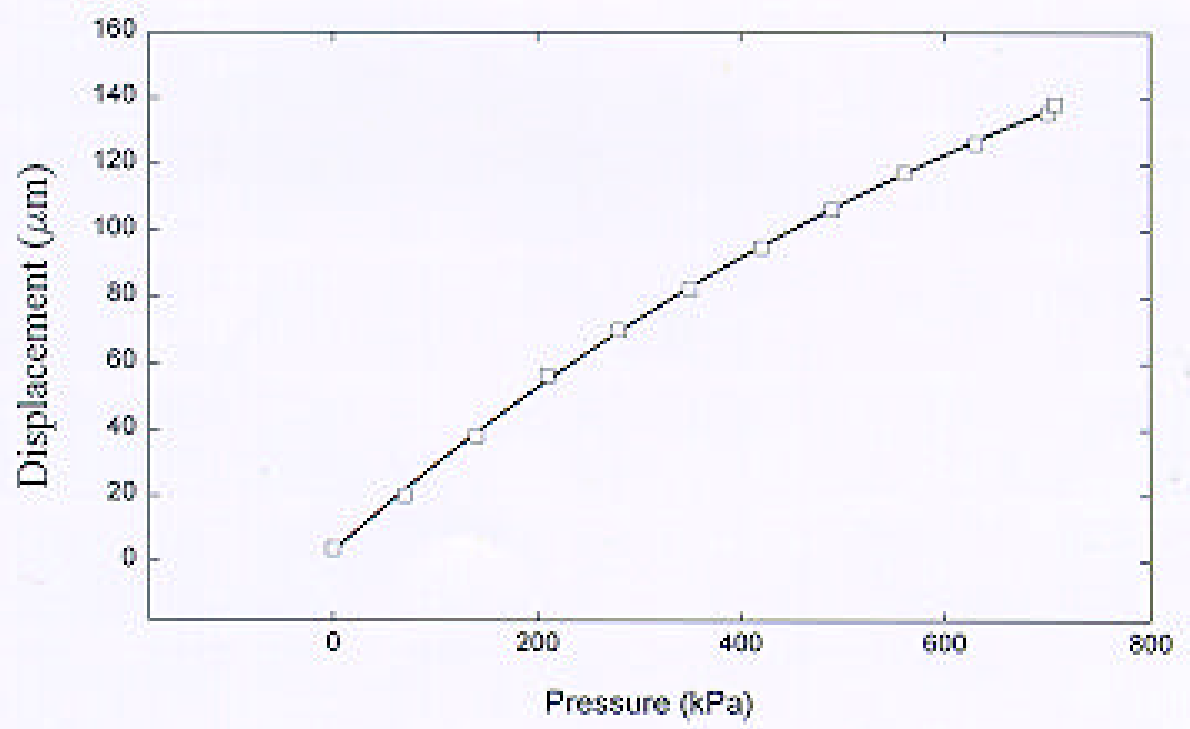

Figure 5. Low pressure (high sensitivity) sensor pressure versus diaphragm displacement. 

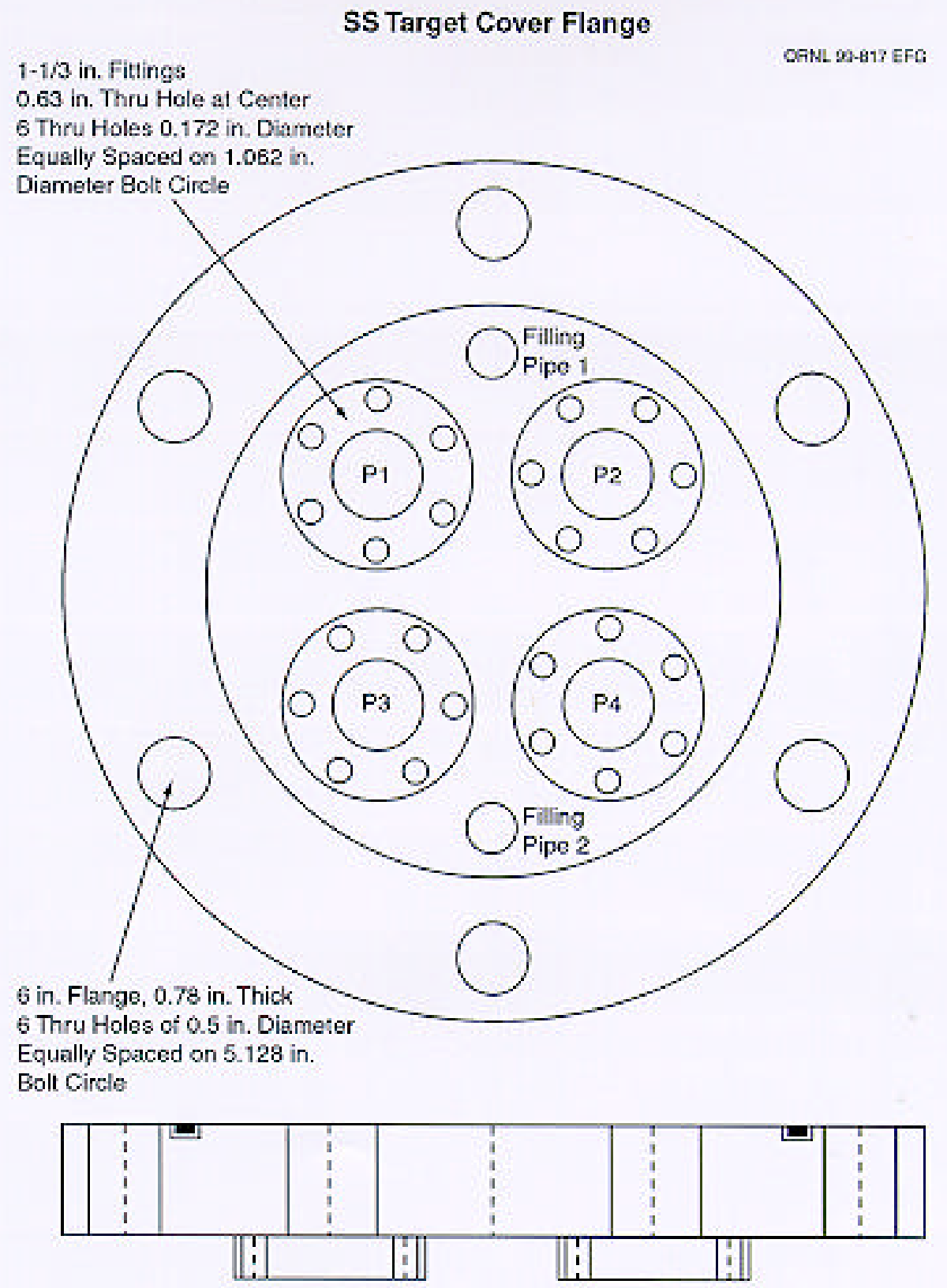

Figure 6. Flange locations on Target A. 

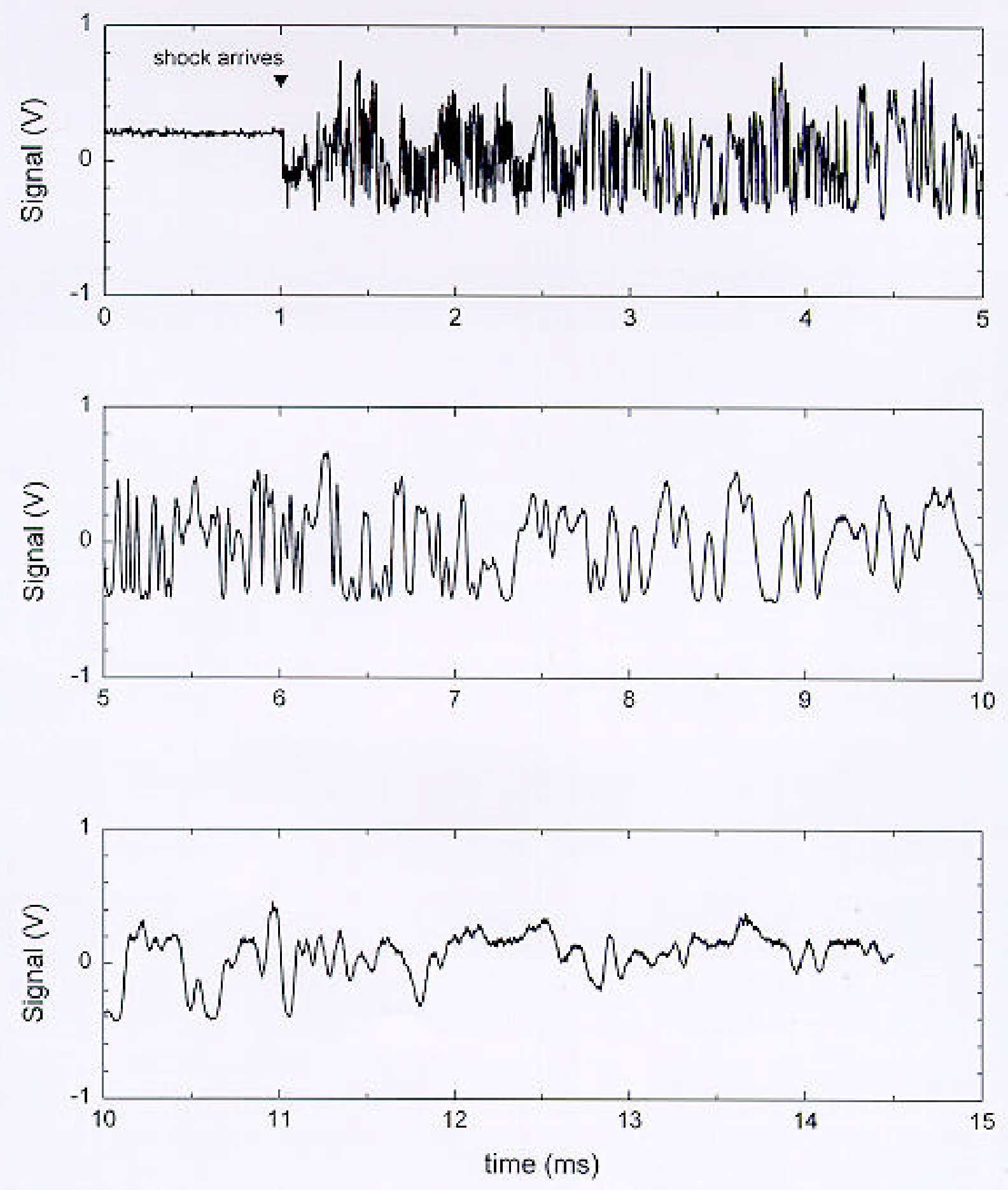

Figure 7. High Pressure Diaphragm Sensor Data for Shot TA-12. 


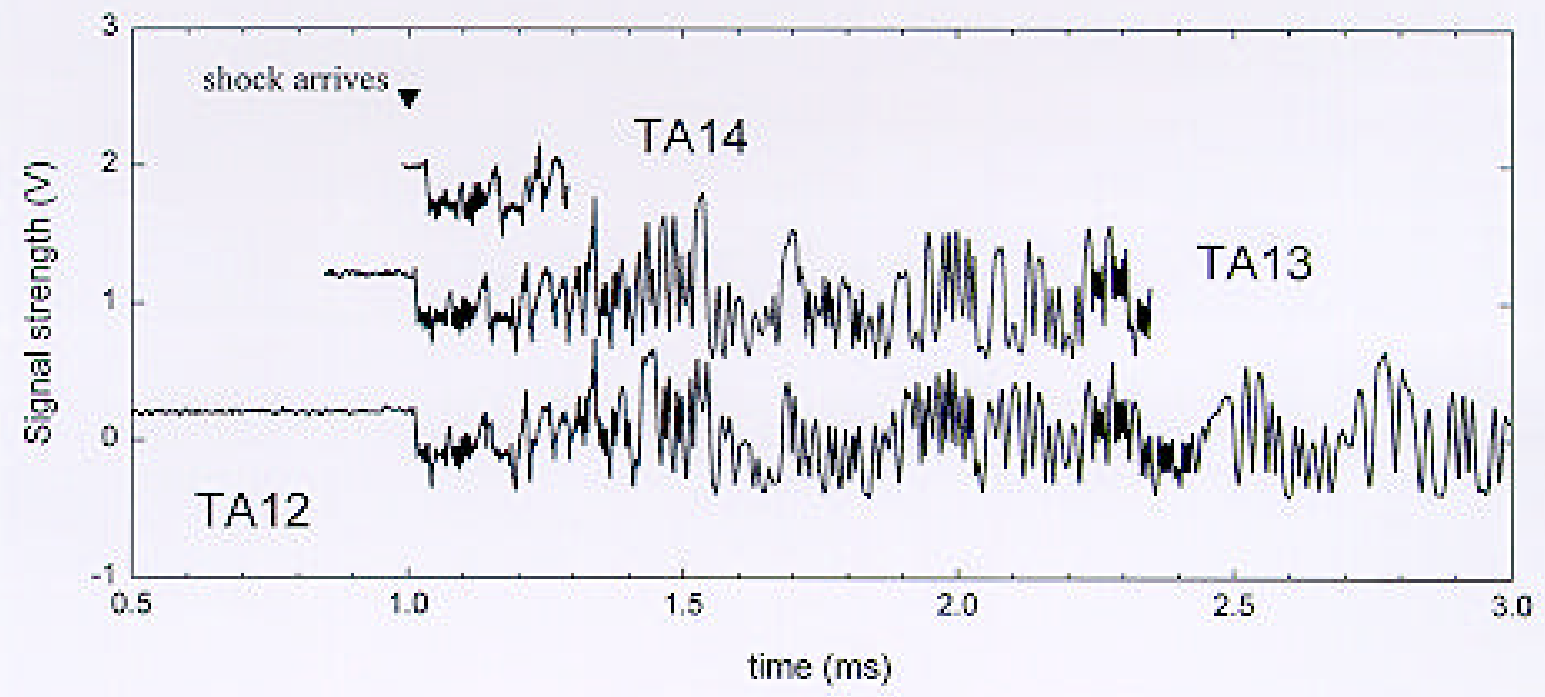

Figure 8. Comparison of Shots TA-12 to TA-14.
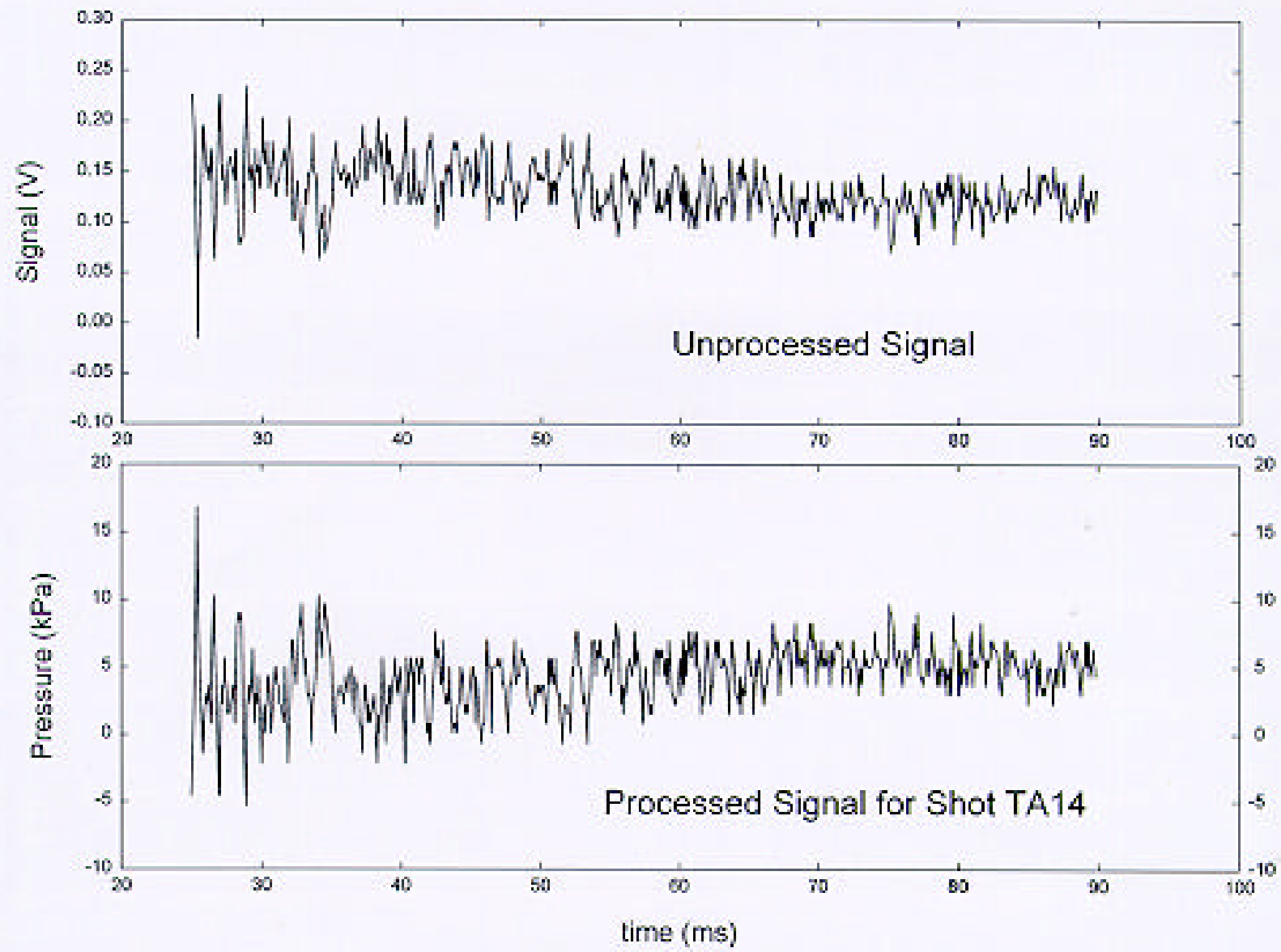

Figure 9. For shot TA-14, unprocessed and processed signal giving pressure vs time. 


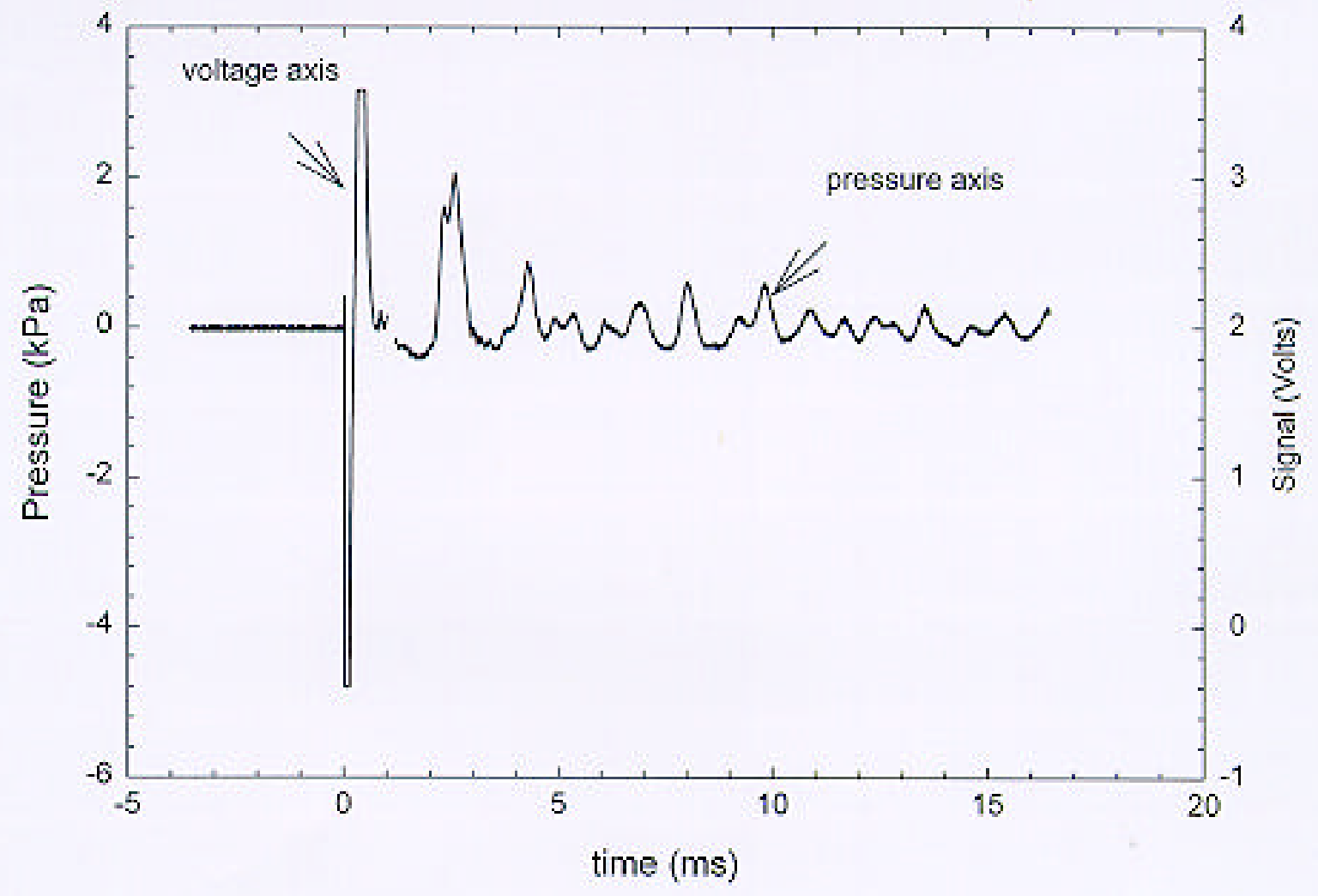

Figure 10. Pressure vs time for Shot TA-35. 